\title{
Current trends and epidemiology on novel covid-19: Pandemic
}

\author{
Manoj Kumar Katual ${ }^{1}$, Gurfateh Singh ${ }^{2}$, S L Harikumar ${ }^{3}$ \\ ${ }^{\mathbf{1}}$ Associate Professor, ${ }^{\mathbf{2}}$ Associate Professor and Head, ${ }^{3}$ Professor, ${ }^{1}$ Rayat-Bahra Institute of Pharmacy, Hoshiarpur, Punjab, ${ }^{2}$ University \\ School of Pharmaceutical Sciences, Rayat-Bahra University, Mohali, Punjab, ${ }^{3}$ Central University of Jharkhand, Ranchi, Jharkhand, India
}

\section{*Corresponding Author: Manoj Kumar Katual}

Email: manojkumar.katual@gmail.com

\begin{abstract}
The novel SARS-CoV-2 corona virus that emerged in the city of Wuhan, China, in 2019 and has since caused a large scale COVID-19 epidemic and spread to more than 190 other countries is the product of natural evolution, according to findings published today in the journal Nature Medicine. Coronaviruses are a large family of viruses that can cause illnesses ranging widely in severity. The first known severe illness caused by a coronavirus emerged with the 2003 Severe Acute Respiratory Syndrome (SARS) epidemic in China. A second outbreak of severe illness began in 2012 in Saudi Arabia with the Middle East Respiratory Syndrome (MERS). On December 31 of last year, Chinese authorities alerted the World Health Organization of an outbreak of a novel strain of coronavirus causing severe illness, which was subsequently named SARS-CoV-2. As of February 20, 2020, nearly 167,500 COVID-19 cases have been documented, although many more mild cases have likely gone undiagnosed. The virus has killed over 6,600 people. Shortly after the epidemic began, Chinese scientists sequenced the genome of SARS-CoV-2 and made the data available to researchers worldwide. The resulting genomic sequence data has shown that Chinese authorities rapidly detected the epidemic and that the number of COVID-19 cases have been increasing because of human to human transmission after a single introduction into the human population. Andersen and collaborators at several other research institutions used this sequencing data to explore the origins and evolution of SARS-CoV-2 by focusing in on several tell-tale feature.
\end{abstract}

Keywords: COVID-19, Severe acute respiratory syndrome.

\section{Introduction}

Corona virus disease 2019 (COVID-19) is an novel infectious disease caused by severe acute respiratory syndrome corona virus 2(SARS-CoV-2). The disease was first identified in 2019 in Wuhan, the capital of Hubei, China, and has since spread globally, resulting in the 201920 corona virus pandemic.

Common symptoms include fever, cough, and shortness of breath. Other symptoms may include muscle pain, sputum production, diarrhea, sore throat, and loss of smell and taste. While the majority of cases result in mild symptoms, some progress to pneumonia and multi-organ failure. As of 25 March 2020, the overall rate of deaths per number of diagnosed cases is 4.5 percent, but it in fact ranges from 0.2 percent to 15 percent according to age group and other health problems. ${ }^{1-3}$

Corona viruses or COVID-19 are a group of related viruses that cause diseases in mammals and birds. In humans, corona viruses cause respiratory tract infections that can be mild, such as some cases of the common cold and others that can be lethal, such as SARS, MERS, and COVID-19.

The name corona virus is derived from Latin corona, meaning "crown" or "halo", which refers to the characteristic appearance reminiscent of a crown or a solar corona around the virus particles when viewed under two dimensional transmission electron microscopy, due to the surface being covered in club-shaped protein spikes. ${ }^{4,5}$

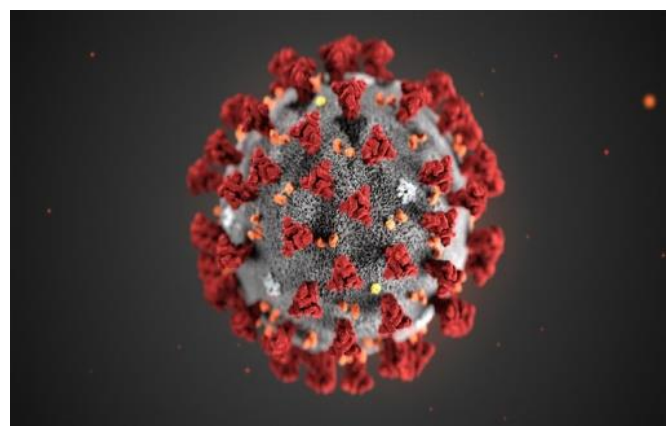

Fig. 1: Novel coronavirus ${ }^{6}$

The virus is typically spread during close contact and via respiratory droplets produced when people cough or sneeze. Respiratory droplets may be produced during breathing but it is not considered airborne. It may also spread when one touches a contaminated surface and then their face. It is most contagious when people are symptomatic, although spread may be possible before symptoms appear. The virus can live on surfaces up to 72 hours. Time from exposure to onset of symptoms is generally between two and fourteen days, with an average of five days. The standard method of diagnosis is by reverse transcription polymerase chain reaction (rRT-PCR) from a nasopharyngeal swab. The infection can also be diagnosed from a combination of symptoms, risk factors and a chest CT scan showing features of pneumonia. ${ }^{7-9}$

Recommended measures to prevent infection include frequent hand washing, social distancing (maintaining physical distance from others, especially from those with symptoms), covering coughs and sneezes with a tissue or inner elbow, and keeping unwashed hands away from the face. The use of masks is recommended by some national 
health authorities for those who suspect they have the virus and their caregivers, but not for the general public, although simple cloth masks may be used by those who desire them. There is no vaccine or specific antiviral treatment for COVID-19. Management involves treatment of symptoms, supportive care, isolation, and experimental measures. The World Health Organization (WHO) declared the 2019-20 corona virus outbreak a Public Health Emergency of International Concern (PHEIC) on 30 January 2020and a pandemic on 11 March 2020. Local transmission of the disease has been recorded in many countries across all six WHO regions. ${ }^{10}$

\section{Historical Background}

An outbreak of the coronavirus (now called COVID-19) in China is causing global concern. It came from a sea food and meat market in Wuhan, China, in December. It has since spread to other countries, including the United States. Despite Wuhan and other Chinese cities being quarantined, the COVID-19 has spread to almost 170 locations internationally. In the U.S., COVID-19 cases have been confirmed and deaths have been reported. It's unclear exactly how contagious the new coronavirus is. It appears to spread from person to person among those in close contact. It may be spread by respiratory droplets released when someone with the virus coughs or sneezes. It may also be spread if a person touches a surface with the virus on it and then touches his or her mouth, nose or eyes. Risk factors for COVID-19 appear to include recent travel from or residence in an area with ongoing community spread ofCOVID-19 as determined by CDC or WHO. Close contact with someone who has COVID-19 such as when a family member or healthcare worker takes care of an infected person. Signs and symptoms of COVID-19 may appear two to14days after exposure and can include Fever, Cough, Shortness of breath or difficulty breathing. Other symptoms can include Tiredness, Aches, Runnynose, Sorethroat etc. ${ }^{11-14}$

\section{Etiology}

The disease is caused by the virus severe acute respiratory syndrome coronavirus 2 (SARS-CoV-2). It is primarily spread between people via respiratory droplets from coughs and sneezes. A study investigating the rate of decay of the virus found no viable viruses after four hours on copper, 24 hours on cardboard, 72 hours on stainless steel, and 72 hours on plastic. However, detection rates did not reach $100 \%$ and varied between surface type (limit of detection was $3.33 \times 100.5$ TCID50 per liter of air for aerosols, 100.5 TCID50 per milliliter of medium for plastic, steel, and cardboard, and 101.5 TCID50 per milliliter of medium for copper). Estimation of the rate of decay with a Bayesian regression model suggests that viruses may remain viable up to 18 hours on copper, 55 hours on cardboard, 90 hours on stainless steel, and over 100 hours on plastic. The virus remained viable in aerosols throughout the time of the experiment (three hours). The virus has also been found in faeces, and transmission through faeces is being researched. The lungs are the organs most affected by
COVID-19 because the virus accesses host cells via the enzyme ACE II, which is most abundant in the type II alveolar cells of the lungs. The virus uses a special surface glycoprotein called a "spike" (peplomer) to connect to ACE II and enter the host cell. The density of ACE II in each tissue correlates with the severity of the disease in that tissue. ${ }^{15-19}$

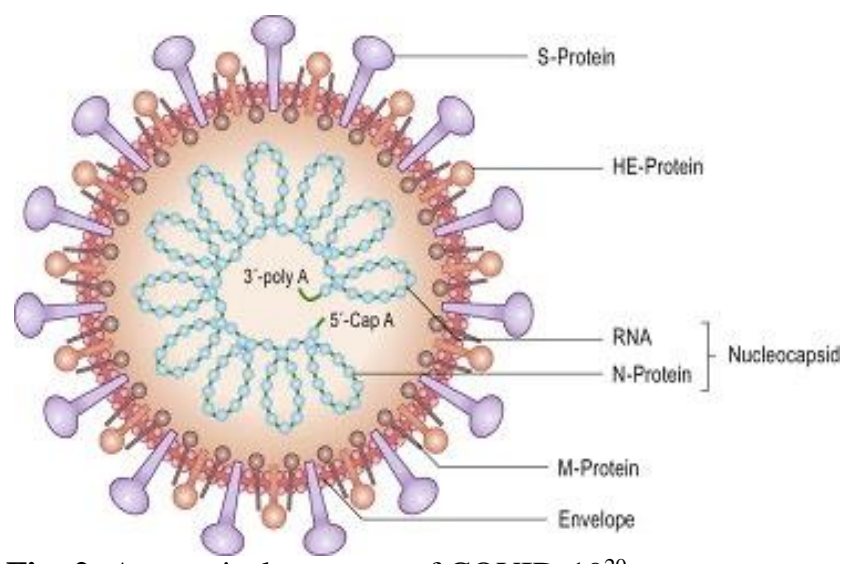

Fig. 2: Anatomical structure of COVID-1920

Some have suggested that decreasing ACE II activity might be protective, though another view is that increasing ACE II using angiotensin II receptor blocker medications could be protective and that these hypotheses need to be tested. As the alveolar disease progresses, respiratory failure might develop and death may follow. ${ }^{22}$

The virus also affects gastrointestinal organs as ACE II is abundantly expressed in the glandular cells of gastric, duodenal and rectal epithelium as well as endothelial cells and enterocytes of the small intestine. The virus has been found in the faeces of as many as 53\% of hospitalised people and more anal swab positives have been found than oral swab positives in the later stages of infection. The virus was found in faeces from 1 to 12 days and $17 \%$ of patients continued to present the virus in faeces after no longer presenting them in respiratory samples, indicating that the viral gastrointestinal infection and the potential fecal-oral transmission can last even after viral clearance in the respiratory tract. Reoccurrence of the virus has also been detected through anal swabs suggesting a shift from more oral positive during the early stages of the disease to more anal positive during later periods. The virus is thought to be natural and have an animal origin, through spillover infection. The origin is unknown but by December 2019 the spread of infection was almost entirely driven by human-to-human transmission. The earliest known infection occurred on 17 November 2019 in Wuhan, China. ${ }^{23-25}$

The disease is caused by the severe acute respiratory syndrome corona virus 2 . It is primarily spread between people during close contact and via respiratory droplets from coughs and sneezes. A study investigating the rate of decay of virus found no viable viruses after four hours on copper, 24 hours on cardboard, 72 hours on stainless steel, 
and 72 hours on plastic. However, detection rates did not reach $100 \%$ and varied between surface types. The disease spreads faster where people are close together or travel between areas. Travel restrictions can reduce the basic reproduction number from 2.35 to 1.05 , allowing the epidemic to be more manageable. Reoccurrence of the virus has been detected through anal swabs suggesting a shift from more oral positive during the early stages of the disease to more anal positive during later periods. ${ }^{26}$

\section{Signs and Symptoms}

Those infected with the virus may be asymptomatic or develop flu-like symptoms, including fever, cough, fatigue, shortness of breath. Emergency symptoms include difficulty breathing, persistent chest pain or pressure, confusion, difficulty walking, and bluish face or lips. Less commonly, upper respiratory symptoms, such as sneezing, runny nose, or sore throat may be seen. Symptoms such as nausea, vomiting, and diarrhea have been observed in varying percentages. Some cases in China initially presented only with chest tightness and palpitations. Loss of the sense of smell and distortion of the sense of taste are reportedly common symptoms among those who are otherwise asymptomatic. In some, the disease may progress to pneumonia, multi-organ failure, and death. In those who develop severe symptoms, time from symptom onset to needing mechanical ventilation is typically 8 days. As is common with infections, there is a delay between the moment when a person is infected with the virus and the time when they develop symptoms. This is called the incubation period. The incubation period for COVID-19 is typically five to six days but may range from two to 14 days. $97.5 \%$ of people who develop symptoms will do so within 11.5 days of infection. ${ }^{27-30}$

\section{Epidemiology}

(Data till 24 ${ }^{\text {th }}$ March 2020) ${ }^{31-35}$

Total cases in world:- $5,49,220$ ( at present increasing day by day)

Total deaths in world:- 24,866 (at present increasing day by day)

Total recovery in world:- $1,28,637$ (at present also increasing)

\section{Statistics}

\begin{tabular}{|l|c|}
\hline Age & Death rate \\
\hline $80+$ years old & $14.8 \%$ \\
\hline $70-79$ years old & $8.0 \%$ \\
\hline $60-69$ years old & $3.6 \%$ \\
\hline $50-59$ years old & $1.3 \%$ \\
\hline $40-49$ years old & $0.4 \%$ \\
\hline $30-39$ years old & $0.2 \%$ \\
\hline $20-29$ years old & $0.2 \%$ \\
\hline $10-19$ years old & $0.2 \%$ \\
\hline
\end{tabular}

\begin{tabular}{|c|c|c|c|c|}
\hline \multicolumn{2}{|c|}{ Location } & \multirow{2}{*}{$\begin{array}{l}\text { Confirmed } \\
\mathbf{7 , 8 4 , 7 1 6}\end{array}$} & \multirow{2}{*}{$\begin{array}{l}\text { Recovered } \\
\mathbf{1 , 6 5 , 3 7 0}\end{array}$} & \multirow{2}{*}{$\begin{array}{l}\text { Deaths } \\
\mathbf{3 7 , 6 3 9}\end{array}$} \\
\hline$\oplus$ & Worldwide & & & \\
\hline$\infty$ & India & 1,251 & 102 & 32 \\
\hline 邫 & United States & $1,63,479$ & 5,604 & 3,146 \\
\hline 10 & Italy & $1,01,739$ & 14,620 & 11,591 \\
\hline 玉 & Spain & 87,956 & 16,780 & 7,716 \\
\hline 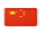 & China & 81,470 & 75,770 & 3,304 \\
\hline 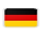 & Germany & 66,885 & 6,522 & 645 \\
\hline w & Iran & 41,495 & 13,911 & 2,757 \\
\hline 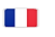 & France & 40,174 & 7,202 & 2,606 \\
\hline 곡든 & $\begin{array}{l}\text { United } \\
\text { Kingdom }\end{array}$ & 22,141 & 135 & 1,408 \\
\hline+ & Switzerland & 15,923 & 2,105 & 354 \\
\hline 10 & Belgium & 11,899 & 1,527 & 513 \\
\hline$=$ & Netherlands & 11,750 & - & 864 \\
\hline c. & Turkey & 10,827 & 162 & 168 \\
\hline $5=$ & South Korea & 9,786 & 5,408 & 162 \\
\hline$=$ & Russia & 1,836 & 66 & 9 \\
\hline C. & Pakistan & 1,717 & 57 & 20 \\
\hline$>$ & Philippines & 1,546 & 42 & 78 \\
\hline$\equiv$ & Thailand & 1,524 & 127 & 9 \\
\hline 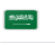 & Saudi Arabia & 1,453 & 115 & 8 \\
\hline- & Indonesia & 1,414 & 75 & 122 \\
\hline$\nRightarrow$ & South Africa & 1,326 & 31 & 3 \\
\hline+ & Finland & 1,308 & 10 & 13 \\
\hline 量 & Greece & 1,212 & 52 & 43 \\
\hline 밤들 & Iceland & 1,086 & 157 & 2 \\
\hline$\therefore$ & Panama & 1,075 & 4 & 24 \\
\hline $1=1$ & Mexico & 993 & 3 & 20 \\
\hline$=$ & Argentina & 966 & 51 & 24 \\
\hline 10 & Peru & 950 & 322 & 24 \\
\hline$=$ & $\begin{array}{l}\text { Dominican } \\
\text { Republic }\end{array}$ & 901 & 3 & 42 \\
\hline$\omega$ & Singapore & 879 & 228 & 3 \\
\hline$=$ & Colombia & 798 & 15 & 14 \\
\hline$=$ & Austria & 9,618 & 636 & 108 \\
\hline $1-1$ & Canada & 7.435 & 1,065 & 89 \\
\hline 0 & Portugal & 6,408 & 43 & 140 \\
\hline 포 & Israel & 4,695 & 161 & 16 \\
\hline$\Rightarrow$ & Australia & 4.514 & 226 & 19 \\
\hline 하ㅁㅡㅡㄹ & Norway & 4,445 & - & 32 \\
\hline 요 & Brazil & 4,330 & 120 & 140 \\
\hline$=$ & sweden & 4,706 & 18 & 161 \\
\hline- & Czechia & 2,976 & 25 & 23 \\
\hline $\mathrm{E}=$ & Denmark & 2.755 & - & 77 \\
\hline a & Malaysia & 2,626 & 479 & 37 \\
\hline II & Ireland & 2,615 & 5 & 46 \\
\hline 므 & Chile & 2,139 & 75 & 7 \\
\hline - & Romania & 2,109 & 209 & 65 \\
\hline- & Poland & 2,055 & 35 & 37 \\
\hline$=$ & Luxembourg & 1.988 & 40 & 22 \\
\hline =iin & Ecuador & 1,890 & 3 & 57 \\
\hline - & Japan & 1,866 & 404 & 54 \\
\hline
\end{tabular}

\section{Global scenario}




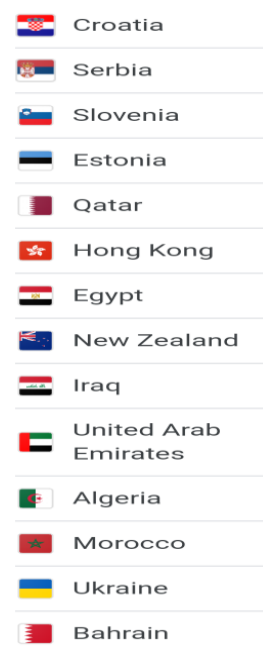

\begin{tabular}{|rrr|}
790 & 64 & 6 \\
\hline 785 & 42 & 16 \\
756 & 10 & 11 \\
715 & 20 & 3 \\
693 & 15 & 14 \\
682 & 124 & 4 \\
656 & 132 & 41 \\
\hline 647 & 74 & 1 \\
630 & 152 & 46 \\
\hline 611 & 61 & 5 \\
\hline 584 & 31 & 35 \\
\hline 556 & 15 & 33 \\
548 & 8 & 13 \\
\hline 515 & 295 & 4 \\
\hline
\end{tabular}

The above mentioned are the countries having more than 500 cases confirmed. Globally it had spread to 211 locations and countries. The world is now desperate to find ways to slow the spread of the novel coronavirus and to find effective treatments. As of Friday (March 20), 86 clinical trials of COVID-19 treatments or vaccines that are either ongoing or recruiting patients. New ones are being added every day, as the case count in the U.S. (and globally) skyrockets. The drugs being tested range from repurposed flu treatments to failed ebola drugs, to malaria treatments that were first developed decades ago. Here, we take a look at several of the treatments that doctors hope will help fight COVID-19. Chloroquine and hydroxychloroquine have been approved by the U.S. Food and Drug Administration for the treatment of malaria, lupus and rheumatoid arthritis, but preliminary research in human and primate cells suggests that the drugs could effectively treat COVID-19. A 2005 study found that chloroquine could quell the spread of SARS-CoV when applied to infected human cells in culture. SARS-CoV is closely related to the novel coronavirus, SARS-CoV-2, and caused an outbreak of severe acute respiratory syndrome in 2002. Chloroquine disrupts the ability of the SARS-CoV virus to enter and replicate in human cells, Live Science previously reported. The cell culture studies of SARS-CoV-2 revealed that the drug and its derivative hydroxychloroquine undermine the novel virus' replication in a similar way. Doctors in China, South Korea, France and the U.S. are now giving the drug to some patients with COVID-19 with promising, albeit anecdotal, results so far. The FDA is organizing a formal clinical trial of the drug. As of Feb. 23, seven clinical trials had been registered in the Chinese Clinical Trial Registry to test whether COVID-19 infections could be treated with hydroxychloroquine. In addition, the University of Minnesota is studying whether taking hydroxychloroquine can protect people living with infected COVID-19 patients from catching the virus themselves. In one heavily referenced study, conducted in France, a small number of patients with COVID-19 received either hydroxychloroquine alone or hydroxychloroquine in combination with an antibiotic called azithromycin. The authors reported that detectable concentrations of SARSCoV-2 fell significantly faster in the study participants than coronavirus patients at other French hospitals who did not receive either drug. In six patients also given azithromycin, this promising effect appeared to be amplified..$^{36-40}$

\section{Impact of Covid-19 Pandemic in India}

The first case of the 2019-20 coronavirus pandemic in India was reported on 30 January 2020, originating from China. As of $27^{\text {th }}$ March 2020, the Indian Council of Medical Research and Ministry of Health and Family Welfare have confirmed a total of 724 cases, 66 recoveries, 1 migration and 17 deaths in the country. The infection rate of COVID-19 in India is reported to be 1.7, significantly lower than in the worst affected countries. On 22 March 2020, India observed a 14-hour voluntary public curfew at the instance of the prime minister Narendra Modi. The government followed it up with lockdowns in 75 districts where COVID cases had occurred as well as all major cities. Further, on 24 March, the prime minister ordered a nationwide lockdown for 21 days, affecting the entire 1.3 billion population of India. ${ }^{41-42}$

\section{All about the Virus}

Coronaviruses are a large family of zoonotic viruses that cause illness ranging from the common cold to severe respiratory diseases. Zoonotic means these viruses are able to be transmitted from animals to humans. There are several coronaviruses known to be circulating in different animal populations that have not yet infected humans. COVID-19 is the most recent to make the jump to human infection. Coronaviruses are important human and animal pathogens. At the end of 2019, a novel coronavirus was identified as the cause of a cluster of pneumonia cases in Wuhan, a city in the Hubei Province of China. It rapidly spread, resulting in an epidemic throughout China, followed by an increasing number of cases in other countries throughout the world. In February 2020, the World Health Organization designated the disease COVID-19, which stands for coronavirus disease 2019. The virus that causes COVID-19 is designated severe acute respiratory syndrome coronavirus 2 (SARSCoV-2); previously, it was referred to as 2019-nCoV. According to the World Health Organization (WHO), viral diseases continue to emerge and represent a serious issue to public health. In the last twenty years, several viral epidemics such as the severe acute respiratory syndrome coronavirus (SARS-CoV) in 2002 to 2003, and H1N1 influenza in 2009, have been recorded. Most recently, the Middle East respiratory syndrome coronavirus (MERS$\mathrm{CoV}$ ) was first identified in Saudi Arabia in 2012. In a timeline that reaches the present day, an epidemic of cases with unexplained low respiratory infections detected in Wuhan, the largest metropolitan area in China's Hubei province, was first reported to the WHO Country Office in China, on December 31, 2019. Some of HCoVs were identified in the mid-1960s, while others were only detected in the new millennium. The CoVs have become the major pathogens of emerging respiratory disease outbreaks. ${ }^{43}$ 


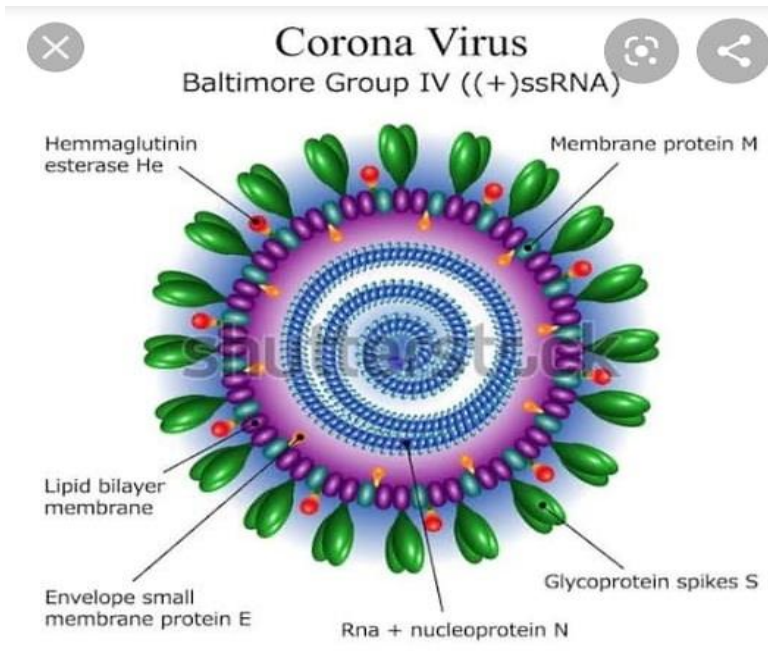

Fig. 3

They are a large family of single-stranded RNA viruses (+ssRNA) that can be isolated in different animal species. For reasons yet to be explained, these viruses can cross species barriers and can cause, in humans, illness ranging from the common cold to more severe diseases such as MERS and SARS. Interestingly, these latter viruses have probably originated from bats and then moving into other mammalian hosts the Himalayan palm civet for SARS-CoV, and the dromedary camel for MERS-Co before jumping to humans. The dynamics of SARS-Cov-2 are currently unknown, but there is speculation that it also has an animal origin. CoVs are positive-stranded RNA viruses with a crown-like appearance under an electron microscope (coronam is the Latin term for crown) due to the presence of spike glycoproteins on the envelope. The subfamily Orthocoronavirinae of the Coronaviridae family (order Nidovirales) classifies into four genera of CoVs: Alphacoronavirus (alphaCoV), Betacoronavirus (betaCoV), Deltacoronavirus (deltaCoV), and Gammacoronavirus (gammaCoV). Furthermore, the betaCoV genus divides into five sub-genera or lineages. Genomic characterization has shown that probably bats and rodents are the gene sources of alphaCoVs and betaCoVs. On the contrary, avian species seem to represent the gene sources of deltaCoVs and gammaCoVs. Members of this large family of viruses can cause respiratory, enteric, hepatic, and neurological diseases in different animal species, including camels, cattle, cats, and bats. To date, seven human $\mathrm{CoVs}(\mathrm{HCoVs})$ capable of infecting humans have been identified. ${ }^{44-48}$

\section{Problem Ccycle}

People may be sick with the virus for 1 to 14 days before developing symptoms. The most common symptoms of coronavirus disease (COVID-19) are fever, tiredness, and dry cough. Most people (about $80 \%$ ) recover from the disease without needing special treatment. More rarely, the disease can be serious and even fatal. Older people, and people with other medical conditions (such as asthma, diabetes, or heart disease), may be more vulnerable to becoming severely ill. Doctors are learning new things about this virus every day. So far, we know that COVID-19 may not initially cause any symptoms for some people. The patient may carry the virus for 2 days or up to 2 weeks before he notice symptoms. Some common symptoms that have been specifically linked to COVID-19 include: shortness of breath, having a cough that gets more severe over time, a low-grade fever that gradually increases in temperature. These symptoms may become more severe in some people. Emergency medical services is needed, if anyone having any of the following symptoms: trouble breathing, blue lips or face, persistent pain or pressure in the chest, confusion, excessive drowsiness. ${ }^{49-50}$

\section{High infection in terms of days}

Day 1: Patients run a fever. They may also experience fatigue, muscle pain, and a dry cough. A small minority may have had diarrhea or nausea one or two days before.

Day 5: Patients may have difficulty breathing, especially if they are older or have a preexisting health condition.

Day 7: This is how long it takes, on average, before patients are admitted to a hospital, the Wuhan University study found.

Day 8: At this point, patients with severe cases develop acute respiratory distress syndrome, an illness that occurs when fluid builds up the lungs. ARDS is often fatal.

Day 10: If patients have worsening symptoms, this is the time in the disease's progression when they're most likely to be admitted to the ICU. These patients probably have more abdominal pain and appetite loss than patients with milder cases. Only a small fraction die: The fatality rate has hovered at about $3 \%$.

Day 17: On average, people who recover from the virus are discharged from the hospital after $21 / 2$ weeks. ${ }^{51-53}$

\section{Preventive Measures}

Preventive measures to reduce the chances of infection include staying at home, avoiding crowded places, washing hands with soap and warm water often and for at least 20 seconds, practicing good respiratory hygiene and avoiding touching the eyes, nose, or mouth with unwashed hands. The CDC recommends covering the mouth and nose with a tissue when coughing or sneezing and recommends using the inside of the elbow if no tissue is available. They also recommend proper hand hygiene after any cough or sneeze. Social distancing strategies aim to reduce contact of infected persons with large groups by closing schools and workplaces, restricting travel, and canceling mass gatherings. Social distancing also includes that people stay at least 6 feet apart (about 1.80 meters).Because a vaccine against SARS-CoV-2 is not expected to become available until 2021 at the earliest, a key part of managing the COVID-19 pandemic is trying to decrease the epidemic peak, known as flattening the epidemic curve through various measures seeking to reduce the rate of new infections. Slowing the infection rate helps decrease the risk of health services being overwhelmed, allowing for better treatment of current cases, and delaying additional cases 
until therapeutics or a vaccine become available. Those diagnosed with COVID-19 or who believe they may be infected are advised by the CDC to stay home except to get medical care, call ahead before visiting a healthcare provider, wear a face mask before entering the healthcare provider's office and when in any room or vehicle with another person, cover coughs and sneezes with a tissue, regularly wash hands with soap and water, and avoid sharing personal household items. The CDC also recommends that individuals wash hands often with soap and water for at least 20 seconds, especially after going to the toilet or when hands are visibly dirty, before eating and after blowing one's nose, coughing, or sneezing. It further recommends using an alcohol-based hand sanitizer with at least $60 \%$ alcohol, but only when soap and water are not readily available. For areas where commercial hand sanitizers are not readily available, WHO provides two formulations for local production. In these formulations, the antimicrobial activity arises from ethanol or isopropanol. Hydrogen peroxide is used to help eliminate bacterial spores in the alcohol; it is "not an active substance for hand antisepsis. Glycerol is added as a humectant. Preventive measures to reduce the chances of infection include staying at home, practicing good respiratory hygiene and avoiding touching the eyes, nose, or mouth with unwashed hands. The CDC recommends covering the mouth and nose with the tissue when coughing or sneezing and recommends using the inside of elbow if no tissue is available Because a vaccine against SARS-COv-2 is not expected to become available until 2021 at the earliest, a key part of managing the COVID-19 pandemic is trying to decrease the epidemic peak, known as "flattening the curve," through various measures seeking to reduce the rate of new infections. ${ }^{54-57}$

\section{Prevention Measure for Community Spreading}

Health care or mortuary staff, or the burial team apply standard precautions, including hand hygiene before and after interaction with the body, and the environment; and use appropriate PPE according to the level of interaction with the body, including a gown and gloves. If there is a risk of splashes from the body fluids or secretions, personnel should use facial protection, including the use of face shield or goggles and medical mask; Prepare the body for transfer including removal of all lines, catheters and other tubes. Ensure that any body fluids leaking from orifices are contained. Keep both the movement and handling of the body to a minimum; Wrap body in cloth and transfer it as soon as possible to the mortuary area. There is no need to disinfect the body before transfer to the mortuary area. Body bags are not necessary, although they may be used for other reasons (e.g. excessive body fluid leakage) and No special transport equipment or vehicle is required. Funeral home/ mortuary care health care workers or mortuary staff preparing the body (e.g. washing the body, tidying hair, trimming nails, or shaving) should wear appropriate PPE according to standard precautions (gloves, impermeable disposable gown or disposable gown with impermeable apron, medical mask, eye protection). If the family wishes only to view the body and not touch it, they may do so, using standard precautions at all times including hand hygiene. Give the family clear instructions not to touch or kiss the body. Embalming is not recommended to avoid excessive manipulation of the body. Adults $>60$ years and immunosuppressed persons should not directly interact with the body. Infection Prevention and Control for dead body management in the context of COVID-19: Interim guidance -2- Autopsy, including engineering and environmental controls Safety procedures for deceased persons infected with COVID-19 should be consistent with those used for any autopsies of people who have died from an acute respiratory illness. If a person died during the infectious period of COVID-19, the lungs and other organs may still contain live virus, and additional respiratory protection is needed during aerosol-generating procedures (e.g. procedures that generate small-particle aerosols, such as the use of power saws or washing of intestines); If a body with suspected or confirmed COVID-19 is selected for autopsy, health care facilities must ensure that safety measures are in place to protect those performing the autopsy; 4 Perform autopsies in an adequately ventilated room, i.e. at least natural ventilation with at least $160 \mathrm{~L} / \mathrm{s} /$ patient air flow or negative pressure rooms with at least 12 air changes per hour $(\mathrm{ACH})$ and controlled direction of air flow when using mechanical ventilation;5 Only a minimum number of staff should be involved in the autopsy; Appropriate PPE must be available, scrub suit, long sleeved fluid-resistant gown, gloves (either two pairs or one pair autopsy gloves), and face shield (preferably) or goggles, and boots. A particulate respirator (N95 mask or FFP2 or FFP3 or its equivalent) should be used in the case of aerosol-generating procedures. Environmental cleaning and control Human coronaviruses can remain infectious on it has been prepared for burial, in accordance with customs. They should not touch or kiss the body and should wash hands thoroughly with soap and water after the viewing. Those tasked with placing the body in the grave, on the funeral pyre, etc., should wear gloves and wash hands with soap and water after removal of the gloves once the burial is complete. Burial by family members or for deaths at home In contexts where mortuary services are not standard or reliably available, or where it is usual for ill people to die at home, families and traditional burial attendants can be equipped and educated to bury people under supervision. Any person (e.g. family member, religious leader) preparing the deceased (e.g. washing, cleaning or dressing body, tidying hair, trimming nails or shaving) in a community setting should wear gloves for any contact with the body. For any activity that may involve splashing of bodily fluids, eye and mouth protection (face shield or goggles and medical mask) should be worn. Clothing worn to prepare the body should be immediately removed and washed after the procedure, or an apron or gown should be worn. The person preparing the body should not kiss the deceased. ${ }^{58-59}$ 


\section{Treatment Available}

In Rajasthan, a combination of anti-malaria, anti-Swine flu and anti-HIV drugs resulted into recovery of three patients in March. In same month, Indian Institute of Chemical Technology, Council of Scientific and Industrial Research and Cipla corporation, launched a joint venture to develop anti-COVID-19 drugs. Pune based Serum Institute of India is expected to apply for clinical trials of certain strains from Drug Controller General of India. As per company president Adar Poonawalla, a vaccine for COVID19 will be delivered within an year, however, it may not be effective on 20 to $30 \%$ people. On 23 March, the National Task Force for COVID19 constituted by Indian Council of risk cases. Medical Research recommended the use of hydroxychloroquine for treatment of COVID19. The WHO has published several testing protocols for the disease. The standard method of testing is real-time reverse transcription polymerase chain reaction (rRT-PCR). The test is typically done on respiratory samples obtained by a nasopharyngeal swab, however a nasal swab or sputum sample may also be used. ${ }^{60}$ Results are generally available within a few hours to two days. Blood tests can be used, but these require two blood samples taken two weeks apart and the results have little immediate value. Chinese scientists were able to isolate a strain of the coronavirus and publish the genetic sequence so that laboratories across the world could independently develop polymerase chain reaction (PCR) tests to detect infection by the virus. As of 19 March 2020, there were no antibody tests though efforts to develop them are ongoing. The FDA approved the first point-of-care test on 21 March 2020 for use at the end of that month. Diagnostic guidelines released by Zhongnan Hospital of Wuhan University suggested methods for detecting infections based upon clinical features and epidemiological risk. These involved identifying people who had at least two of the following symptoms in addition to a history of travel to Wuhan or contact with other infected people: fever, imaging features of pneumonia, normal or reduced white blood cell count, or reduced lymphocyte count. One study in China found that CT scans showed ground-glass opacities in $56 \%$, but $18 \%$ had no radiological findings. Bilateral and peripheral ground glass opacities are the most typical CT findings, though they are non-specific. Consolidation, linear opacities and reverse halo sign are other radiological findings. Initially, the lesions are confined to one lung, but as the disease progresses, indications manifest in both lungs in $88 \%$ of socalled "late patients" in the study group (the subset for whom time between onset of symptoms and chest CT was 6-12 days). Ground-glass opacities are also a common feature in children's disease.

Chloroquine approved for emergency use by US FDA. The US Food and Drug Administration (FDA) approved limited emergency use for chloroquine and hydroxychloroquine as a treatment for COVID-19.The President of the United States, Donald Trump, had announced on 19 March that chloroquine and hydroxychloroquine/Plaquenil, used to treat malaria and arthritis, were approved by the FDA to be tested as a treatment for COVID-19.Chloroquine is being tested in various clinical trials conducted by government agencies and academic institutions. Other antivirals drugs are also planned to be fast-tracked for testing for coronavirus. Favilavir, the first approved coronavirus drug in China. The National Medical Products Administration of China has approved the use of Favilavir, an anti-viral drug, as a treatment for coronavirus. The drug has reportedly shown efficacy in treating the disease with minimal side effects in a clinical trial involving 70 patients. The clinical trial is being conducted in Shenzhen, Guangdong province. Pharmaceutical companies involved in developing coronavirus drugs/vaccines here is a list of the major coronavirus drugs that pharmaceutical companies across the world are developing that have the potential to become major coronavirus vaccines or antivirals for treating the contagious coronavirus infection. ${ }^{61}$

\section{Novel coronavirus vaccines}

Listed below are the coronavirus vaccines in various stages of development, across the world.

\section{Fusogenix DNA vaccine by Entos Pharmaceuticals}

Entos Pharmaceuticals is developing Fusogenix DNA vaccine developed using the Fusogenix drug delivery platform to prevent COVID-19 infections. Fusogenix drug delivery platform is a proteo-lipid vehicle that introduces genetic payload directly into the cells. Entos is working on developing an optimised payload containing multiple protein epitopes derived from SARS-COV-2 proteins, which will stimulate an immune response in the body to prevent COVID-19 infection.

\section{ChAdOx1 nCoV-19 by University of Oxford}

The University of Oxford's ChAdOx1 nCoV-19 is an adenovirus vaccine vector developed by the university's Jenner Institute. The university is testing the vaccine in a clinical trial planned to be conducted in the Thames Valley Region. Approximately 510 volunteers aged between 18 years and 55 years will be enrolled for the study.

\section{Gimsilumab by Roivant Sciences}

Roivant Sciences is advancing the development of Gimsilumab a clinical-stage, human monoclonal antibody. The drug targets granulocyte-macrophage colony stimulating factor (GM-CSF), which is a pro-inflammatory cytokine found in high levels in the serum of COVID-19 patients. Targeting GM-CSF is expected to reduce lung damage and reduce mortality rate in COVID-19 patients.

\section{AdCOVID by Altimmune}

Altimmune has collaborated with the University of Alabama at Birmingham (UAB) to develop a single dose intranasal vaccine for COVID-19 named AdCOVID. The company is currently carrying out immunogenicity studies after, which phase one clinical trial material will be developed. Altimmune and UAB will work with researchers to conduct 
preclinical animal studies and phase one clinical trial in the third quarter of 2020.

\section{TJM2 by I-Mab Biopharma:}

I-Mab Biopharma is developed TJM2, a neutralising antibody, as a treatment for cytokine storm in patients suffering from a severe case of coronavirus infection. The drug targets the human granulocyte-macrophage colonystimulating factor (GM-CSF), which is responsible for acute and chronic inflammation. The company will commence development after receiving approval for the Investigational New Drug (IND) application from the U.S. Food and Drug Administration (FDA).

\section{Coronavirus vaccine by Medicago:}

Medicago is developing drug candidates against COVID-19 after having produced Virus-Like Particles (VLP) of the coronavirus. The company has formed a collaboration with Laval University's Infectious Disease Research Centre to develop antibodies against SARS-CoV-2. ${ }^{62}$

\section{Management of Covid-19}

People are managed with supportive care, which may include fluid, oxygen support, and supporting other affected vital organs. Steroids such as methylprednisolone are not recommended unless the disease is complicated by acute respiratory distress syndrome. The $\mathrm{CDC}$ recommends that those who suspect they carry the virus wear a simple face mask. Extracorporeal membrane oxygenation (ECMO) has been used to address the issue of respiratory failure, but its benefits are still under consideration. While the WHO does not oppose the use of non-steroidal anti-inflammatory drugs such as ibuprofen for symptoms, some recommend paracetamol (acetaminophen) for first-line use There are four reported cases of children who developed severe symptoms after taking ibuprofen. While theoretical concerns have been raised about ACE inhibitors and angiotensin receptor blockers, as of 19 March 2020 these are not sufficient to justify stopping these medications. The WHO and Chinese National Health Commission have published recommendations for taking care of people who are hospitalised with COVID19.Intensivists and pulmonologists in the US have compiled treatment recommendations from various agencies into a free resource, the IBCC. ${ }^{63-64}$

\section{Personal protective equipment}

Precautions must be taken to minimize the risk of virus transmission, especially in healthcare settings when performing procedures that can generate aerosols, such as intubation or hand ventilation, respirator or facemask, gown, medical gloves, eye protection. ${ }^{65}$

\section{Mechanical ventilation}

Most cases of COVID-19 are not severe enough to require mechanical ventilation (artificial assistance to support breathing), but a percentage of cases do. Some Canadian doctors recommend the use of invasive mechanical ventilation because this technique limits the spread of aerosolized transmission vectors. Severe cases are most common in older adults (those older than 60 years and especially those older than 80 years). Many developed countries do not have enough hospital beds per capita, which limits a health system's capacity to handle a sudden spike in the number of COVID-19 cases severe enough to require hospitalization. This limited capacity is a significant driver of the need to flatten the curve (to keep the speed at which new cases occur and thus the number of people sick at one point in time lower). One study in China found 5\% were admitted to intensive care units, $2.3 \%$ needed mechanical support of ventilation, and $1.4 \%$ died. Every ventilator is worth its weight in gold as a source says a third of all Coronavirus patients could need it. A number of organizations are using 3D printing to produce various needed equipment. ${ }^{66}$

\section{Psychological support}

Individuals may experience distress from quarantine, travel restrictions, side effects of treatment, or fear of the infection itself. To address these concerns, the National Health Commission of China published a national guideline for psychological crisis intervention on 27 January $2020 .{ }^{67}$

\section{Role of individuals}

According to ICMR, if a person suffer from the symptoms of the same symptom of covid-19 (as mentioned above) must call the helpline no.112 and visit to hospital and consult with the doctor. He should have to obey the instruction as per provided by the government. He should have to drink the warm water, and avoid to come in contact with the other persons. He should have to wear the mask and wash the hand with the sanitizer or anything else. He should have to avoid to sit or gossips in making groups. ${ }^{68}$

\section{Oath for all Indivisual toward Prevention of Covid- 19}

I will follow all the instruction provided by the government and will not go outside when there is not a extremely urgent work. I will give the knowledge about the covid-19 to the family and relative and also restrict them to go outside the home. I will advise my family to maintain social distances. I will protect myself from covid-19 and also protect the people by protecting myself because it is transmitted from one to another.

\section{Conclusion}

The corona virus, which is found in animals and, rarely, can be transmitted from animals to humans and then spread person to person. It cause acute respiratory disease. It's symptoms closely relate with pneumonia. Coronavirus destroy cilia in the respiratory tract and cell death occurs. All sensible indivisuals are required not to drop any post related to Corona virus, which has not been verified from a reliable source. It has been declared a punishable offense by the Government, only a government agency can post on Corona. In case of wrong post or message, action will be 
taken against the members including the area administrator by registering a lawsuit under the IT Act, so keep in mind be safe!. Practicing everyday prevention is necessary. As we touch people, surfaces and objects throughout the day, we accumulate germs on our hands. We can infect our self with these germs by touching your eyes, nose or mouth. As No drugs or biologics have been proven fully to be effective for the prevention or treatment of COVID-19 till date. Numerous antiviral agents, immunotherapy, and vaccines are being investigated and developed as potential therapies. Searching for effective therapies for COVID-19 infection is a complex process. According to the WHO, the most common symptoms of Covid-19 are fever, tiredness and a dry cough. Some patients may also have a runny nose, sore throat, nasal congestion and aches and pains or diarrhoea. Some people report losing their sense of taste and/or smell. About $80 \%$ of people who get Covid-19 experience a mild case about as serious as a regular cold and recover without needing any special treatment. About one in six people, the WHO says, become seriously ill. The elderly and people with underlying medical problems like high blood pressure, heart problems or diabetes, or chronic respiratory conditions, are at a greater risk of serious illness from Covid-19. The most common way that this illness spreads is through close contact with someone who has the infection. Close contact is within around 6 feet. The disease is most contagious when a person's symptoms are at their peak. However it is possible for someone without symptoms to spread the virus. A new study suggests that $10 \%$ of infections are from people exhibiting no symptoms. Droplets containing the virus can also land on nearby surfaces or objects. Other people can pick up the virus by touching these surfaces or objects. Infection is likely if the person then touches their nose, eyes, or mouth. Preparing and packing the body for transfer from a patient room to an autopsy unit, mortuary, crematorium, or burial site Ensure that personnel who interact with the body. Maintain social distance and Stay safe.

\section{Acknowledgement}

The authors are highly thankful to all staff members of University School of Pharmaceutical Sciences, Rayat-Bahra University, Mohali, Punjab, India for their constant encouragement and support for preparing this article. The authors hereby declare no conflict of Interest.

\section{Source of Funding}

None.

\section{Conflict of Interest}

None.

\section{References}

1. World Health Organization. Director-General's remarks at the media briefing on 2019-nCoV on 11 February 2020.

2. World Health Organization. Novel coronavirus situation report-2. January 22, 2020. sitrep-2-2019-ncov.pdf.
3. Rothe C, Schunk M, Sothmann P. Transmission of 2019-nCoV Infection from an Asymptomatic Contact in Germany. $N$ Engl J Med. 2020;382:970.17.

4. Kupferschmidt K. Study claiming new coronavirus can be transmitted by people without symptoms was flawed. Science. February 3, 2020.

5. Bai Y, Yao L, Wei T. Presumed Asymptomatic Carrier Transmission of COVID-19. JAMA. 2020.

6. Li Z, Yi Y, Luo X, Xong N, Liu Y, Li S, et al. Development and clinical application of a rapid $\operatorname{IgM}-\operatorname{IgG}$ combined antibody test for SARS-CoV-2 Infection diagnosis. J Med Virol. 2020.

7. Centers for disease control and prevention. interim clinical guidance for management of patients with confirmed 2019 novel coronavirus (2019-nCoV) Infection, February 12, 2020.

8. Li Q, Guan X, Wu P. Early Transmission Dynamics in Wuhan, China, of Novel Coronavirus-Infected Pneumonia. $N$ Engl J Med. 2020.

9. Guan WJ, Ni ZY, Hu Y. Clinical Characteristics of Coronavirus Disease 2019 in China. N Engl J Med. 2020.

10. Chan JF, Yuan S, Kok KH. A familial cluster of pneumonia associated with the 2019 novel coronavirus indicating personto person transmission: a study of a family cluster. Lancet. 2020;395:514.

11. Wu Z, McGoogan JM. Characteristics of and important lessons from the coronavirus disease 2019 (COVID-19) outbreak in China: Summary of a Report of 72314 Cases From the Chinese Center for Disease Control and Prevention. JAMA. 2020.

12. Huang $\mathrm{C}$, Wang $\mathrm{Y}, \mathrm{Li} \mathrm{X}$. Clinical features of patients infected with 2019 novel coronavirus in Wuhan, China. Lancet. 2020;395:497.

13. Chen N, Zhou M, Dong X. Epidemiological and clinical characteristics of 99 cases of 2019 novel coronavirus pneumonia in Wuhan, China: a descriptive study. Lancet. 2020; 395:507.

14. https://www.who.int/docs/default-source/coronaviruse/whochina-joint-missionon-covid-19-final-report.pdf.

15. National Center for Immunization and Respiratory Diseases (NCIRD), Division of Viral Diseases

16. Xia W, Shao J, Guo Y, Peng X, Li Z, Hu D. Clinical and CT features in pediatric patients with COVID-19 infection: Different points from adults. Pediatr Pulmonol. 2020. doi: 10.1002/ppul.24718.

17. https://www.who.int/docs/default-source/coronaviruse/whochina-joint-mission-oncovid-19-final-report.pdf

18. https://www.ecdc.europa.eu/en/case-definition-and-europe ansurveillance-human infection-

19. novel-coronavirus-2019-ncov

20. Vital Surveillances: The Epidemiological Characteristics of an Outbreak of 2019 Novel Coronavirus Diseases (COVID-19) China, 2020.

21. https://www.worldometers.info/coronavirus/coronavirus-agesex-demographics/

22. https://www.who.int/docs/default-source/coronaviruse/whochina-joint-missionon-covid-19-final-report.pdf

23. https://www. who.int/docs/default-source/coronaviruse/whochina-joint-missionon-covid-19-final-report.pdf

24. https://www.ecdc.india.eu/en/case-definition-and-india:ansurveillance-human infection novel - coronavirus-2019-ncov

25. https://www.ecdc.europa.eu/en/case-definition-and-europe ansurveillance-human infection- novel-coronavirus-2019-ncov

26. https://onlinelibrary.wiley.com/doi/epdf/10.1002/jmv.25727 Development and Clinical Application of A Rapid IgM_IgG Combined Antibody Test for SARS_CoV_2 Infection Diagnosis

27. https://pubs.rsna.org/doi/10.1148/radiol.2020200823.Performa nce of radiologists in differentiating COVID-19 from viral pneumonia on chest CT. 
28. Bouadma L, Lescure FX, Lucet JC, Yazdanpanah Y, Francois J. Severe SARS-CoV-2 infections: practical considerations and management strategy for intensivists.

Timsit.https://link.springer.com/content/pdf/10.1007/s00134020-05967-x.pdf.

29. Arabi YM, Asiri AY. Treatment of Middle East respiratory syndrome with a combination of lopinavir/ ritona vir and interferon-_1b (MIRACLE trial): statistical analysis plan for a recursive two stage group sequential randomized controlled trial.

30. Arabi YM, Shalhoub S, Mandourah Y, Al-Hameed F, AlOmari A, Al Qasim E. Ribavirin and interferon therapy for critically ill patients with middle east respiratory syndrome: A multicenter observational study. Clin Infect Dis. 2020;70(9):1837-44.

31. Moskowitz A, Yankama T, Andersen LW, Huang DT, Donnino MW, Grossestreuer AV, et al. Ascorbic Acid, Corticosteroids and Thiamine in Sepsis (ACTS) protocol and statistical analysis plan: a prospective, multicentre, doubleblind, randomised, placebo-controlled clinical trial. $B M J$ Open. 2019;9(12):e034406.

32. Wang M, Cao R, Zhang L, Yang $X^{1}$, Liu J, Xu M, et al. Remdesivir and chloroquine effectively inhibit the recently emerged novel coronavirus (2019-nCoV) in vitro. Cell Res. 2020;30(3):269-71.

33. https://www.who.int/publications-detail/global-surveillancefor-human-infection-withnovel- coronavirus-(2019-ncov).

34. Radonovich LJ, Simberkoff MS. Bessesen MT. N95 respirators vs medical masks for preventing influenza among health care personnel a randomized clinical trial. JAMA. 2019;322(9):824-33.

35. Loeb M, Dafoe N, Mahony J, John M, Sarabia A, Glavin V, et al. Surgical Mask vs N95 respirator for preventing influenza among health care workers - A randomized trial. JAMA. 2009;302(17):1865-71.

36. MacIntyre CR. Cauchemez S, Dwyer DE, Seale H, Cheung $\mathrm{P}$, Browne G, et al. Face Mask Use and Control of Respiratory Virus Transmission in Households. Emerg Infect Dis. 2009; 15(2):233-41.

37. Bryant PA, Trinder J, Curtis N. Sick and tired: does sleep have a vital role in the immune system?. Nat Rev Immunol. 2004;4(6):457-67.

38. Exercise and the Immune System - Brolinson (2007).

39. Kampfa G. Persistence of corona viruses on inanimate surfaces and their inactivation with biocidal agents.

40. Guan W, Ni Z. Yu Hu, Liang W, Ou C, He J, Liu L. Clinical Characteristics of Coronavirus Disease 2019 in China. $N$ Engl J Med. 2020;382;18.

41. Guan W, Ni Z, Yu Hu, Liang W, Ou C, He J, et al. Clinical Characteristics of Coronavirus Disease 2019 in China. Novel Coronavirus Infection in Hospitalized. $N$ Engl J Med. 2020;382:1708-20.

42. Infants Under 1 Year of Age in China. JAMA. 2020 Feb 14. doi: 10.1001/jama.2020.2131.

43. Holshue ML, DeBolt C, Lindquist S, Lofy KH, Wiesman J, Bruce H, et al. First Case of 2019 Novel Coronavirus in the United States. N Engl J Med. 2020;382(10):929-36.

44. Hoehl S, Rabenau H. Evidence of SARS-CoV-2 Infection in Returning Travelers from Wuhan, China. $N$ Engl J Med. 2020;382:1278-80.

45. Kampf G, Todt D, Pfaender S, Steinmann E. Persistence of coronaviruses on inanimate surfaces and their inactivation with biocidal agents. J Hosp Infect. 2020;104(3):246-51.

46. Wahidi MM, Lamb C, Murgu S, Musani A, Shojaee S, Sachdeva A, et al. American Association for Bronchology and Interventional Pulmonology (AABIP) statement on the use of bronchoscopy and respiratory specimen collection in patients with suspected or confirmed covid-19 Infection. J Bronchology
Interv Pulmonol. 2020 Mar 18. doi: 10.1097/LBR.0000000000000681.

47. Vitalograph: Hygiene Considerat ions for Spirometry. First published in Primary Care Today. 2011. pp. 1-3. Available from https://vitalograph.com/resources/article/hygieneconsiderations-for-spirometry.

48. Rasam SA, Apte KK, Salvi SS. Infection control in the pulmonary function test laboratory. Lung India. 2015;32(4):359-66

49. 1-Guan WJ, Ni ZY, Hu Y. Clinical characteristics of coronavirus disease 2019 in China. N Engl J Med. 2020. doi: 10.1056/NEJMoa2002032.

50. National Health Commission of the People's Republic of China. Diagnosis and treatment plan of novel coronavirus pneumonia (Version-7) (2020-03-04). http://www.nhc.gov.cn /yzygj/s7653p/202003/46c9294

a7dfe4cef80dc7f5912eb1989.shtml.

51. Ma HJ, Shao JB, Wang YJ. High resolution CT features of novel coronavirus pneumonia in children. Chin J Radiol. 2020;54. DOI: 10.3760/c ma.j.issn.1005-1201.2020.0002

52. Sztrymf B, Messika J, Mayot T, Lenglet H, Dreyfuss D, Ricard JD. Impact of high-flow nasal cannula oxygen therapy on intensive care unit patients with acute respiratory failure: A prospective observational study. J Crit Care. 2012;27:324:e913.

53. The National Heart, Lung, and Blood Institute Acute Respiratory Distress Syndrome (ARDS) Clinical Trials Network. Comparison of two fluid-management strategies in acute lung injury. $N$ Engl J Med. 2006;354:2564-75.

54. Dellinger RP. Surviving sepsis campaign: international guidelines for management of severe sepsis and septic shock: 2008. Crit Care Med. 2008;36:296-27.

55. Papazian L, Forel JM, Gacouin A. Neuromuscular blockers in early acute respiratory distress syndrome. $N$ Engl J Med. 2010;363:1107-16.

56. Sud S, Friedrich JO, Taccone P. Prone ventilation reduces mortality in patients with acute respiratory failure and severe hypoxemia: systematic review and meta-analysis. Intensive Care Med. 2010;36: 585-99.

57. Beckman S, Materna B, Goldmacher S, Zipprich J, D'Alessandro M, Novak D. Evaluation of respiratory protection programs and practices in California hospitals during the 2009-2010 H1N1 influenza pandemic. Am J Infect Control. 2013;41(11):1024-31.

58. Janssen L, Zhuang Z, Shaffer R. Criteria for the collection of useful respirator performance data in the workplace. J Occup Environ Hyg. 2014;11(4):218-26.

59. Janssen LL, Nelson TJ, Cuta KT. Workplace protection factors for an N95 filtering facepiece respirator. J Occup Environ Hyg. 2007;4(9):698-707.

60. Ong SWX, Tan YK, Chia PY, Lee TH, Ng OT, Wong MSY, Marimuthu K. Air, Surface Environmental, and Personal Protective Equipment Contamination by Severe Acute Respiratory Syndrome Coronavirus 2 (SARS-CoV-2) From a Symptomatic Patient. JAMA. 2020. doi: 10.1001/jama.2020.3227

61. https://www.bbc.com/news/world-asia-china-51395655

62. https://nypost.com/2020/03/13/second-newborn-baby-testspositive-for-coronavirus/

63. Guidelines on use of masks for health care workers, patients and members of public. Ministry of health and family welfare. Government of India.

64. Kanne JP, Little BP, Chung JH, Elicker BM, Ketai LH Essentials for Radiologists on COVID-19: An updateradiology scientific expert panel. Radiol. 2020;200527.

65. Pan F, Ye T, Sun P, Gui S, Liang B, Li L, et al. Time course of lung changes on chest CT during recovery from 2019 novel coronavirus (COVID-19) Pneumonia. Radiol. 2020;77(8):1-15. 
66. Shi H, Han X, Jiang N, Cao Y, Alwalid O, Gu J, et al. Radiological findings from 81 patients with COVID-19 pneumonia in Wuhan, China: a descriptive study. Lancet Infect Dis. 2020;3099(20):1-10.

67. Buonsenso D, Piano A, Raffaelli F, Bonadia N. Point-of-care lung ultrasound findings in novel coronavirus disease-19 pnemoniae: a case report and potential applications during COVID-19 outbreak. Eur Rev Med Pharmacol Sci. 2020; 24:2776-80.

68. Peng QY, Wang XT, Zhang LN. Critical C, Ultrasound C, Group S. Findings of lung ultra sonography of novel corona virus pneumonia during the 2019-2020 epidemic. Intensive Care Med. 2020;(87):6-7.

How to cite: Katual MK, Singh G, Harikumar SL. Current trends and epidemiology on novel covid-19: Pandemic. $J$ Educ Technol Health Sci. 2020;7(1):3-13. 